\title{
Critical conversations: Social workers' perceptions of the use of a closed Facebook group as a participatory professional space
}

\author{
Deb Stanfield ${ }^{1}$, Liz Beddoe ${ }^{2}$, Neil Ballantyne ${ }^{3}$, Simon Lowe ${ }^{4}$ and Nicole Renata ${ }^{2}$
}

${ }^{1}$ Wintec, New Zealand

${ }^{2}$ University of Auckland, New Zealand

${ }^{3}$ Open Polytechnic, New Zealand

${ }^{4}$ University of Waikato, New Zealand
AOTEAROA

NEW ZEALAND SOCIAL WORK 29(3), 42-54.

CORRESPONDENCE TO: Deb Stanfield deb.stanfield@xtra.co.nz

\begin{abstract}
INTRODUCTION: The rise of social media has been associated with rapid growth in different forms of digital networking, debate and activism. Many studies have traced the role of social media in mobilising people to take action on shared issues of concern across the world. Yet, while networked public spaces offer many possibilities for professional engagement and interaction, the technology also shapes social dynamics, raising questions over professional boundaries and the nature of online behaviour.

METHODS: The development of a closed professional group on the social networking site, Facebook, provided an ideal opportunity to explore social workers' perceptions of participatory public space for professional deliberation and debate about public issues. Using a smallscale, case-study approach, group members were invited to complete an online survey and to participate in an interview which explored participants' motivation for joining the group, the frequency and nature of their contributions, how it felt to be a member and what they valued or found problematic about the group.
\end{abstract}

FINDINGS: Those group members benefitted from the resources, research and professional development opportunities afforded to them and supported the professional potential and promise of social networking sites. They grappled with what constitutes ethical online behaviour and identified the site's limitations and strengths as a place to promote robust professional dialogue on social issues.

IMPLICATIONS: Analysis of social workers' experience within participatory public spaces offers insight into how the profession can develop modern communication strategies and strong communities of practice in line with its professional principles and mandate.

Keywords: social media; professional boundaries; social networking sites; netiquette

The growth of social media has been associated with a rapid development of different forms of digital activism and social networking. Facebook and Twitter have been identified as having the capacity to coordinate large events, to support public debate and to mobilise people into action (boyd, 2011; Levine, 2000; Varnelis \& Friedberg, 2008). For example, the Occupy Movement and the Arab Spring of 2011 have been studied for the role social media played in the dissemination of information, and in political and social change (Fuchs, 2014a, 2014b; Valenzuela, 2012).

Social media have been described as opening up networked public spaces, or participatory publics, where people can engage in open, deliberative, democratic 
debate within shared communities of practice (Gerbaudo, 2012,2015; Joyce, 2010, Tierney, 2013). Yet, whilst the affordances of networked public space offer many possibilities for engagement and interaction, the technology also shapes social dynamics: altering the nature of the public and private expression of political ideas and introducing less desirable possibilities such as blurred boundaries, collapsed contexts, conflict and concerns about surveillance (boyd, 2011). In addition, the commercial nature of most social media (for example, Facebook) has been considered by some commentators to be in direct conflict with the principles of social justice: imposing limits on freedom of expression and exploiting user content (Fuchs, 2014b). From a social work perspective, the profession has been called upon to consider both the impact and potential of social media including: its significant influence on everyday social interaction, its potential for new forms of practice and its prospective power as a tool for advocacy on social justice issues (Simpson, 2017; Stanfield \& Beddoe, 2016; Wolf \& Goldkind, 2016).

This topic is a new field of study in Aotearoa New Zealand. The project reported in this article is unique in that it captures the views of a group of social workers who voluntarily participate in a professional space in social media. The focus of our inquiry is a Facebook group called Social Work in Aotearoa New Zealand (SWANZ): at the time of the study this was a closed group of over 850 members administered and moderated by a single individual social worker. The group was set up in October 2014 with the administrator establishing the aim as providing "a safe place for social workers in Aotearoa New Zealand to meet and discuss issues relevant to our practice". This was a closed group, meaning that the sole administrator approved membership and had a role in managing the content of the page. Belonging to a Facebook group is different to having a personal Facebook account in that individual members are unable to choose who is a member of the group, and will not necessarily know all members personally.

This exploratory case study aimed to explore three questions: what members valued most about their participation in a Facebook group for social workers; what problems they experienced; and what influenced the degree of their participation. The findings may assist in the development of the professional use of social media by social workers and other professional groups. This article presents findings from the analysis of data gathered in semistructured interviews. These interviews enabled the researchers to explore in greater depth themes which emerged from a survey conducted within the case study (Ballantyne, Lowe, \& Beddoe, 2017).

\section{Literature review}

This study explores the opinions and experience of social workers as members of a closed professional Facebook group; as such, literature related to shared online meeting places that offer opportunity for professional dialogue are considered within the scope of this review, specifically referred to as social networking sites (SNSs).

\section{Social networking sites and social media}

The emergence of social media offers the public new ways to create and maintain relationships, to share information and to collaborate (Graham, Jackson, \& Wright, 2015; Sage \& Sage, 2016). Social networking sites provide internet-based services that allow people to engage with social media in a unique way: to construct a digital identity and connect socially without barriers of time or space (Fuchs, 2014a; Steinfield, Ellison, \& Lampe, 2008).

Social media is a term often used interchangeably with online social networking and an important distinction is noted here for 
the purpose of this article. A critical understanding of social media as a broad concept is based on analysis of what is meant by the words social and media, and by understanding the historical context of the phenomenon (Fuchs, 2014b). Some critics promote the collaborative, democratic potential of social media (Jenkins, Clinton, Purushotma, Robison, \& Weigel, 2009; Kaplan \& Haenlein, 2010) while others are critical of the economic, marketing origins of the major social media platforms and the exploitive impact this has on users (Fuchs, 2014b).

Social networking sites, on the other hand (e.g., Facebook and LinkedIn), provide a framework within which social media is shared. Other ways to do this include blogging (WordPress), microblogging (Twitter), or by sharing specific contentmusic and film media or photography (YouTube, Instagram). The key features of SNSs as distinct from other platforms are the use of profiles and a particular, unique way of connecting with others:

SNSs are web-based platforms that integrate different media, information and communication technologies that allow at least the generation of profiles that display information describing the users, the display of connections (connection list), the establishment of connections between users displayed on their connection lists, and communication between user. (Fuchs, 2014b, p. 254)

The creation of SNSs has led to what has been coined networked publics (boyd, 2011) describing the ways in which people use internet technology to gather for personal, professional and political reasons, to seek information and for civic engagement (De Zuniga \&

Valenzuela, 2011; Graham et al, 2015). Social networking sites share a similar function to real world meeting spaces, for example cafés or workplaces (Varnelis \& Friedberg, 2008).
While networked publics share much in common with other types of public places, the ways in which technology structures the environment also shapes interpersonal communication (Varnelis \& Friedberg, 2008). New dynamics emerge as a result of the online context, with factors like the absence of non-verbal cues and a lack of vocal tone making it harder for people to decode interpersonal communications (Anderson, Brossard, Scheufele, Xenos, \& Ladwig, 2014; Mohan, McGregor, \& Strano, 1992). Granovetter (1973) categorised networked connections into strong and weak ties, and cites relationship quality as influential within social interaction.

The conceptual tools of Bourdieu's field theory have been applied extensively to the use of online communication, including attention to habitus and social capital (Julien, 2015; Lambert, 2016; Willig, Waltorp, \& Hartley, 2015). Social networking sites provide an opportunity for individuals to develop their social networks and gain social capital, two known factors understood to contribute to psychological wellbeing. Steinfield et al. (2008) broadly describe social capital as the benefits one receives from social relationships. Warren, Sulaiman, and Jaafar (2015) describe users of SNSs with a high number of online friends as perceived to have more social capital than a person with fewer friends.

This study focusses on the use of Facebook, currently the most popular social networking site. By the third quarter of 2016 Facebook reported 1.79 billion active monthly users (Statista, 2016). As mentioned, profiles are central to SNSs like Facebook and include demographic information, photos, and newsfeeds which track social interactions. The acquisition of friends is crucial to social networking, and networks can be extended by joining or following groups, events or public figures (Kolek \& Saunders, 2008; Longlois, Elmer, Mckelvery, \& Devereux, 2009; Valenzuela, 2012). The SWANZ group referred to in this article is an example of one of these groups. 


\section{Social media, social networking sites and social work}

As noted earlier, there is a paucity of research about how social workers engage with social media generally, or with SNSs specifically. Current social work literature offers insight into the relationship between social media and social work education (Cooner, 2013; Kellsey \& Taylor, 2016; Megele, 2014; Westwood, 2014), and guidance to social workers in their ethical use of social media (Boddy \& Dominelli, 2016; Dombo, Kays, \& Weller, 2014; Kimball \& Kim, 2013; Reamer, 2015). Important thinking and research has been put forward about use of social media and internet technology in practice (Ryan \& Garrett, 2017; Sage \& Sage, 2016; Sitter \& Curnew, 2016). There is a call from the literature for an increased focus on, and analysis of, social media by the social work profession and for this to be done critically and quickly (Edwards \& Hoeffer, 2010; Wolf \& Goldkind, 2016).

Research that explores how social workers perceive, engage with and integrate their personal and professional social media presence will provide new information to support the development of digital policy and the design and use of participatory public spaces as communities of practice. Social media offer multiple practice possibilities, from progressing the collective social justice causes of social work to providing a digital space for discussion, debate and support. The evolution of social media use also presents social justice challenges that require attention. Moving into this important professional space therefore requires support from robust social work research and analysis; this exploratory study makes an initial contribution.

\section{Method}

This study was opportunistic given that the emergence of a Facebook group for professional social workers-a new phenomenon in Aotearoa New Zealandrepresented a naturally occurring opportunity to explore the benefits and limitations of social networking for professional purposes. If the researchers had had the freedom to consider any methodological approach to investigate this phenomenon, we would have been inclined towards digital ethnography: a particularly valuable way of exploring what it means for professional social workers to be digitally engaged in a networked public space (Pink et al., 2016). Such an approach would have enabled us to capture actual online interactions between participants as the primary data source, yielding rich empirical data and allowing the researchers to adopt an inductive approach to theory building. However, as discussed in relation to the survey conducted within this case study (Ballantyne et al., 2017), the ethical complexities of seeking informed consent for an ethnographic approach in a pre-existing Facebook group led the researchers to reject that approach.

Instead, we adopted a case-study design frame including survey and interview methods of data collection. As Thomas (2011) argues, a case has to be a case of something, that something constituting its analytical frame. In this study, the SWANZ Facebook group is the "practical historical unity" (Thomas, 2011, p. 513) that forms the subject of analysis, but it is a case of a networked public space used for professional purposes which forms the object, or analytical frame of the study. However, it is important to note that, following Thomas (2011), we are not claiming that the subject of our study is representative or typical of the wider analytical frame, merely that it is a local example of the wider object of study. Furthermore, like many case studies, this one adopts an ideographic stance, focussing on the unique features of the case rather than seeking to generalise to other instances. To be more precise, using the typology developed by Thomas (2011), this study is a local case study, with exploratory purposes taking an illustrative/descriptive approach on retrospective data in a single case. 
The SWANZ Facebook group provided an ideal environment to explore the experience of social workers using SNSs. It is a closed group, comprised of professional social workers who had decided to join the group of their own volition and who, by virtue of having a personal Facebook page, showed willingness to engage in social media activity.

This case study utilised an online survey (responses $N=53$ ) and 11 semi-structured interviews to explore the following three research questions:

1. What do participants value about their membership of the SWANZ Facebook group?

2. What problems or issues are associated with membership?

3. What factors are associated with active engagement and with reluctance to participate in the SWANZ community?

The low response to the survey was disappointing and possible reasons for this are discussed later under limitations. With consent from the group administrator, an invitation to participate in the survey was placed in the SWANZ Facebook group, and the invitation post was repeated on several occasions. A link to a participant information sheet about the research was provided-it was explicit that participation in the survey indicated informed consent. The questionnaire included mostly quantitative questions designed to collect demographic information, data about the participants' general use of Facebook and their political activism, and their use of use of, and experiences, in the SWANZ group. Interview participants were drawn from those who completed the survey and indicated interest in further engaging with the research questions. Interviews were conducted soon after the participant made contact and were held while the survey was still open.

\section{Ethical concerns}

The project was approved by the ethics committees of two universities, the University of Waikato and the University of Auckland. No potentially identifying information was required from participants and the survey software was set to anonymise responses by scrubbing technical identifiers. Those completing the survey were asked to leave a name and contact details if they were willing to contribute further via an interview. If participants elected to offer an interview they were sent further information and a consent form by the fifth author, who conducted the interviews. Contact information was separated from the survey data. Interviews were audio-recorded and transcribed.

\section{Findings}

The focus of this article is on the findings from the interviews; however, it is useful to briefly outline the survey findings here as they largely support data gathered from the interviews (Ballantyne et al., 2017). Most survey participants valued many aspects of the group, with over $75 \%$ reporting that the group helped them feel connected to a wider community of practice and enabled them to share and have access to relevant professional information. Just under $50 \%$ of participants felt they were able to use membership of the group to take a stand, or question or challenge the views of government. A majority encouraged other social workers to become involved in the group; however, over a third considered leaving the group at some time for reasons of uncivil behaviour by other members; over $70 \%$ of participants were reluctant to express their political views openly (Ballantyne et al., 2017).

\section{Interviews}

Eleven semi-structured interviews were conducted by phone or Skype. All but one participant described their ethnicity as NZ European or Pākehā. The age range was 31-40 $(n=1) ; 41-50(n=5) ; 51-60(n=5)$ and there were nine women and two men. The data generated by this small, exploratory procedure enabled an inductive thematic approach involving completion of descriptive coding levels. Two members 
of the research team contributed to the coding of themes. A thorough reading of all transcripts and careful textual coding of the data using NVivo assisted the generation of themes. Our approach reflects Braun and Clarke's approach to organic thematic analysis where researchers:

... routinely generate themes and develop complex analyses from smaller samples. This isn't just because themes in organic TA are constructed rather than found. It is because a process of fine-grained coding captures diversity and nuance, and provides a foundation for conceptualising possibly significant patterns (for research questions) of shared meaning [emphases in the original]. (2016, p. 742)

The interviews sought to gather more in-depth information in order to explore the three research questions stated above. The interview participants had completed the online survey, and had an opportunity to further consolidate their views prior to the interview thereby offering further/deeper thoughts about the topic. The themes generated from the interviews included those related to professional belonging or connection, access to professional information, the nature and purpose of using the Facebook group, the level and nature of engagement in the group; safety and the ethical issues.

\section{A place to meet}

Interview participants acknowledged the SWANZ Facebook page as a good place to make collegial connections, to build a sense of professional community and solidarity. These qualities are referred to both as a reality and as an ideal:

... an excellent way to stay in touch with my professional community and learn what people were up to, hear anecdotes of people's practice and what they were reading and thinking about and ideas about what was happening in the country and how it was affecting their work and what people were changing or seeing.
All of that kind of thing, a way for us to connect with each other. (Participant \#1)

These qualities were also those understood to have potential and, at times, reflected the as-yet unrealised expectations of the participants; for example, the desire to connect and develop relationships that are unique to the profession of social work, a certain camaraderie:

Who totally understands that it's going to take an hour to get to your client and they're not going to be there and you're looking for the green house with the red roof. It's all those sorts of things that help that inter-relatedness. I'd love to see that, that would be really exciting. People just sharing with their agencies and their stories and stuff like that. I think that if you promote stuff like that, get people on board then that'll grow. (Participant \#2)

\section{Access to professional information}

Participants appreciated the capacity of the Facebook group to expose a range of current practice issues including poverty, racism, legislative changes and global events impacting on social work. They were also grateful for being guided towards free, open-access journal articles and other forms of knowledge and research relevant to practice, and noted the generosity of members who did this for them. There was acknowledgement of the group as a unique place to access these resources because they were recommended by respected colleagues, as such the group performing an editorial or curative function:

... a bit of curation that I don't have to do because like most people in practice or in education the amount of new stuff that is being generated all the time is just impossible to keep up with. So if someone's recommending an article or if someone's done a bit of reading and chosen some articles or they're the ten most read articles or something I find that really useful to have that curation 
function done for me and then I can have a look at them. (Participant \#3)

The lack of time and ability to stay connected with current social issues was a problem noted by many participants. The Facebook group offered not only a forum for information sharing, but also a place to offer analysis of that information from a social work perspective:

... things like the TPP, people just glaze over because there's such a massive ... piece of information, any of these trade agreements are but if you give people the main points and how it affects our sovereignty and takes power away from us and our clients, most social workers will go "you know what, that really sucks". (Participant \#4)

On the other hand, participants acknowledged the limitations of some information shared and were, at times, critical of the professional quality offered to the group as uncritical or "flaky". There was also caution expressed about the usefulness of some information shared based on a lack of clarity about who was sharing it and what their motivations might be for doing so:

I think that that's one of the challenges in online forums is that things can get misrepresented because people's passions are tied to what they're presenting or are tied to particular issues and it can go down a whole track that you don't want it to go down and you can be perceived wrong, positioned wrong, misunderstood. All those things happen in life but you're at a disadvantage that online there's no context, there's no context to who you are and what you've done in your history and for people to understand where you're coming from. (Participant \#5)

\section{Making sense of participation and dialogue}

Participants commented not only on the type of information valuable (or not) to them in the group, but also on how dialogue around issues was structured, the nuances of online communication, and the success of this as measured with their hopes for the group:

You might say a generalised statement and then someone says a comment to you and you think "oh, I hadn't thought about that, you're right". You peel back the layers and you think I'll look a bit deeper into this. That's why I like the discussion. I don't even mind-there were some people, one or two that I thought were quite-I wouldn't say ignorant but I'd just say fitted in with the dominant discourse and I didn't even mind their comments because it gave others the opportunity to challenge them. And to me it's really nice for me to listen to like-minded people because I have felt a little bit in isolation with my values and passions. (Participant \#6)

The excitement and appeal of genuine dialogue as a way of learning and developing communities of practice was countered by worry about the possibility of conflict and the impact that public disagreement on issues could have on the profession:

... you're sort of turning on your allies, people who are close to you and so I really worry that this ongoing thing is actually just polarising our community into not just two but potentially more and more factions and meanwhile ... the right and the massive changes to social work ... just march on almost unopposed because we're too busy scrapping.

(Participant \#1)

\section{Level of engagement/participation}

The sense participants made of how the Facebook group operated is related to the level of engagement they had with others in the group and their overall participation. Decisions made about participation levels were based on a number of factors, including a sense of hierarchy within the profession and perceived value of their contributions. 
For example, it was thought that students without practice experience or new practitioners felt less able to contribute than social work academics.

... sometimes I feel like I'm perhaps not qualified enough or academic enough so I don't mind just listening to stuff. A lot of my class belong to it and a lot of them do read the stuff but I don't see them posting anything. Maybe they feel like me, we're still students so we don't really have that experience or the qualifications yet to comment. (Participant \#6)

Confidence, or perception of worth may also lead to decisions about actively participating in discussions:

It triggers I think many of us to think we're not worth shit in this world and social work belongs to all those smart people and not to us ... and I'll only ever learn something by reading something someone else has written but I won't ever, I can't ever contribute and form knowledge myself ... it is actually that Black American poet who said "how can I tell you who I am, if you don't believe I'm real" and I think, I think that statement for me really gets me in the gut cause that's a dynamic that I see playing out... (Participant \#7)

Many participants expressed a view that the impersonal nature of the social media environment (for example, not personally knowing members or seeing them face to face) contributed to their lack of trust in engaging with the SWANZ group. However, there were other personality or motivational traits linked to levels of participation:

I think some people contribute more because they just do. I guess it depends if people feel really passionate about that and maybe give certain factors or they absolutely want to have a say and I think some people are content just to read and maybe think about what's there, maybe don't feel so strongly ... or maybe put off because I think sometimes some of the comments and the things that people post can be a bit off-putting if you have a different opinion. (Participant \#8)

A question was posed by one participant about the cultural limitations of Facebook as a place to fully engage in genuine dialogue and some tentative thoughts were offered about this:

... if you do express yourself it may be that you feel more inspired to start that through waiata or the use of the reo or looking at ancestral marae and then speaking from there about your own truth so the context is quite important. I'm unsure if Facebook always provides a context that may be broad enough to allow multiple people to speak... (Participant \#7)

Most participants described themselves as observers rather than active participants on the SWANZ group. This finding aligns with the survey results which reported a majority of participants rarely or never started new posts in the SWANZ group, and just over half sometimes or often commented on the posts of others (Ballantyne et al., 2017).

\section{Netiquette}

The term netiquette in this context encompasses all activities on social networking sites that require attention to behaviour and how we regulate it to ensure safety, conformity, ethical or professional conduct. This particular theme, also described as "online incivility" (Anderson et al., 2014; Papacharissi, 2004), was identified strongly in the qualitative analysis of comments made on the SWANZ group online survey where we noted concerns raised about online incivility and "a pervasive reluctance to express policy or political opinions because of concerns about critical comments by others" (Ballantyne et al., 2017, p. 34). As seen earlier, the desirability of online behaviour was a factor in deciding whether or not to engage with 
the group. Interview participants wondered about the place of professional ethics and conduct in providing guidelines for online communities of social work practice and recommended that such guidelines be developed and used; however, they also identified subtler understandings of what online civility means:

I felt that people were being put off engaging because it wasn't a safe space and of course it's sold as a safe space and I think that it's not about not challenging, it's about challenging in a way that actually is a place of respect. I don't feel like that was really in existence for a long time. (Participant \#1)

Participants acknowledged their role in de-escalating the dialogue of others, as well as carefully monitoring the nature and tone of their participation by censoring and mindfully composing their contributions:

I manage comment really carefully because one of the things for me that's in this forum, it's really easy to have intended or unintended consequences that affect other people and you don't realise you're doing it so you do need to have a really cool head and be focused on what you're actually saying and why you're saying it and what possible readings of it could be. (Participant \#5)

Professional netiquette also encompasses the continual negotiation of personal and professional boundaries and, as in other professional contexts, consideration of what constitutes the personal and professional leads to clear decisions about how to behave in a professional context:

I've seen stuff on that site and go ... I'm not entering into that. That sounds personal, it sounds like you're actually working out your frustration in here and I don't want to enter into that dialogue because I don't want to be hooked into something that's not cool. (Participant \#9)

\section{Discussion}

The SWANZ Facebook group was used as the subject in this case study to explore and analyse the use of participatory public spaces for professional social work purposes (Thomas, 2011). Interview participants were asked to retrospectively describe their experience as members of the group, and the rich descriptive insights offered showcase social workers grappling with familiar concepts of professional identity, relationship and ethics within the new ecosystem of a social networking site. In attempting to understand what has happened for them in this particular online environment, they have applied principles of social justice, equality, their knowledge of social discourse and, in some cases, used their skills and ethics to manage communication with a diverse range of people in a unique space.

Social workers in the group hoped to support professional homogeneity by creating a unique set of accepted online professional behaviours. This can be understood further by considering participant social capital, the advantages gained by membership of particular networks. In the case of the SWANZ Facebook group, members could employ their capital both to bond with others to create solidarity, and as a bridge to a diversity of perspectives (Ellison, Lampe, Steinfield, \& Vitak, 2011). On the other hand, if the benefits of belonging to the group are not realised, or social capital is not gained (for example, members feeling unworthy of contributing because of perceived power differentials), participants experience some reluctance to engage. Social capital usually has exclusionary effects, serving to reproduce structures of power, as indicated by the participants quoted above who felt they did not always have the confidence to post or comment.

In addition, consideration of habitus, for example, offers insight into the impact of professional and cultural influences on participation and the degree to which 
these align with the everyday practices of social networking (Willig et al., 2015).

Participants expressed perceptions of discords between cultural practice and social media affordances, and between professional ethics and the online behaviour of some members, thereby limiting their willingness to participate. There was a clear recognition, for example, that the medium did not always allow for the nuanced discussion that might occur in a more familiar professional setting.

Participants reflected the idea that we are still learning how to operate in this new kind of professional milieu, as boyd (2011) notes, "as social network sites and other genres of social media become increasingly widespread, the distinction between networked publics and publics will become increasingly blurry" (p. 55). She further suggests that the dynamics mapped out in an online environment will gradually, and inevitably, become part of everyday life.

Further analysis of social workers operating in online environments provides opportunity to monitor, develop and more actively shape professional identity.

A focus on netiquette, or ethical online behaviour, has growing academic and professional support for social workers and social work academics (Reamer, 2015; Harbeck-Voshel \& Wesala, 2015) and the results of this work are beginning to make their way into organisational codes of conduct. The Social Workers Registration Board (SWRB) in Aotearoa New Zealand, for example, has only recently made reference to professional use of social media in its revised Code of Conduct (SWRB, 2016). The participants in this project raised the issue of online safety and recognised the absence of a code of ethics to guide them in their online communications. The link between professional ethics and online safety, however, is tenuous. The presence of social media challenges us to reconsider our traditional binary understandings of public and private (boyd, 2010; Fuchs, 2014b) with closed groups seemingly offering safety that is perhaps illusory when the group is large and contains many people unknown to each other. Social workers are challenged to develop an understanding of this particular feature of social media so that they can go beyond a reliance on codes of conduct to best make critical, mature use of it as professionals.

Despite the call for ethical guidelines, social workers interviewed for this study discussed using their professional skills and knowledge to make decisions about how to behave online. By considering the best way to make comments or choose material to post, for example, they disclosed using de-escalation techniques to manage growing conflict; they provided support to those sharing difficult personal experiences; used inclusive language and understanding of social discourse to analyse issues and prevent the perpetuation of harmful narratives. Further analysis of the online behaviour of social workers would support a deep, grassroots understanding of the profession as it is evolving in the $21^{\text {st }}$ century-how it is influencing, and being influenced by, its social media environment.

Facebook provides an architecture that enables the creation of unique groups of people. The SWANZ group has now grown to more than 1200 social workers. Since its inception, this group has had opportunity to define itself, to expand or contract, to develop subgroups with more refined identities, all the while negotiating what it means to be a social worker, what its mandate is as a group of people and generating thoughts about myriad bewildering social issues and events. Although in the following quote Fuchs is referring to the use of social media more widely, there is wisdom in considering how the structure of social networking sites influences our intentions:

One needs unity in diversity in order to struggle for participatory democracy and for maintaining this condition once it is reached. It is preferable and more effective to have a few widely 
accessible and widely consumed broad critical media than many small-scale special interest media that support the fragmentation of struggles. (Fuchs, 2014a, p. 64)

The current social work literature identifies the profession as inadequately engaged with the phenomenon of social media and therefore at risk of missing key opportunities to be involved in its critique and development (Edwards \& Hoeffer, 2010; Wolf \& Goldkind, 2016). One reason given for this reticence is that technology continues to be seen by social workers as "representing an intrusion into the person-centred project of social work" (Steyaert \& Gould, 2009, p. 58). This position does not acknowledge the key place social media hold in our environment or in the parallel, historic journey that social work and the media share:

Today blogs are the new pamphlets. Microblogs and online networks are the new coffee houses. Media sharing sites are the new commonplace books. They are all shared, social platforms that enable ideas to travel from one person to another, rippling through networks of people connected by social bonds, rather than having to squeeze through the privileged bottleneck of broadcast media. The rebirth of social media in the internet age represents a profound shift-and return, in many respects, to the way things used to be. (Standage, 2013, p. 250)

These words offer inspiration to those who work with victims of inequality and privilege. The "old" media of printing presses and broadcasters is interpreted by Standage (2013) as a 19th century colonisation of how human beings had communicated for centuries. The role of social work is to be actively involved in this decolonisation, and in the creation and critique of new ways of interacting and bringing together activists, service users and professionals in innovative responses to social problems and public issues.

\section{Limitations}

Attention to netiquette, including the management of professional boundaries was an important theme drawn from the analysis of these interviews, and this key feature of networked public spaces also played out in the research process. Most of the research team were members of the SWANZ Facebook group at the time of the study therefore our participation in the study was as "insider researchers" (Dwyer \& Buckle, 2009). As such, in the development of our research questions and the analysis of the data gathered we cannot be innocent of bias. As Dwyer and Buckle (2009) assert:
We cannot retreat to a distant "researcher" role. Just as our personhood affects the analysis, so, too, the analysis affects our personhood. Within this circle of impact is the space between. The intimacy of qualitative research no longer allows us to remain true outsiders to the experience under study and, because of our role as researchers, it does not qualify us as complete insiders. We now occupy the space between, with the costs and benefits this status affords. (p. 62)

The research team were disappointed with the response to the survey; however, as insider researchers cannot deny the possible impact their membership of the group had on the low rate of participation. The association of some research team members with a conflict occurring within the group at the time may have had a negative effect on willingness to participate; this partially explaining our failure to recruit the 20\% we had hoped for. Another limitation could have been the time of year (summer holidays) the survey was run.

We did slightly exceed our goal of recruiting 10 participants for interviews, however, we note that some of both interview and survey participants mentioned the conflict in the group. While this discussion is apposite to the study research questions, it does suggest 
the possibility of skewing factors. Potential and actual participants may have been influenced in their decision to participate by their attitudes towards those enmeshed in the conflict in the SWANZ group.

These matters considered, and the small sample with low ethnic and gender diversity means that we should be cautious about generalising from these results. The themes do resonate with the findings reported in other literature (Ballantyne et al., 2017; Boddy \& Dominelli, 2016; Kimball \& Kim, 2013; Megele, 2014; Reamer, 2015; Ryan \& Garrett, 2017; Sage \& Sage, 2016; Stanfield \& Beddoe, 2016; Westwood, 2014; Wolf \& Goldkind, 2016).

\section{Conclusions}

Further analysis of the behaviour and experience of social workers using social media, and specifically social networking sites, is crucial to the development of a profession able to respond as effectively as possible to current social challenges. The ability to use social networking sites as professional tools, to understand the "architecture" of social networking sites and their influence on the tasks of social work, democracy and social justice, and to make the most of our professional relationships in this forum relies on developing further knowledge of this ubiquitous form of communication. The small number of participants in this study highlighted both the many challenges and the rewards of engaging in a closed social work Facebook group; they also expressed a fascination with the dynamics of that experience, and some hope about the promise of online social networking.

\section{References}

Anderson, A. A., Brossard, D., Scheufele, D. A., Xenos, M. A., \& Ladwig, P. (2014). The "nasty effect": Online incivility and risk perceptions of emerging technologies. Journal of Computer-Mediated Communication, 19(3), 373-387.

Ballantyne, N., Lowe, S., \& Beddoe, L. (2017). To post or not to post? Perceptions of the use of a closed Facebook group as a networked public space. Journal of
Technology in Human Services, 35(1), 20-37. doi:10.10 80/15228835.2017.1277903

Boddy, J., \& Dominelli, L. (2016). Social media and social work: The challenges of a new ethical space. Australian Social Work, 1-13. doi:10.1080/0312407x.2016.1224907

boyd, d. (2011). Social networking sites as networked publics: Affordances, dynamics, and implications. In Z. Papacharissi (Ed.), A networked self: Identity, community, and culture on social network sites (pp. 39-58). New York, NY: Routledge.

Braun, V., \& Clarke, V. (2016). (Mis)conceptualising themes, thematic analysis, and other problems with Fugard and Potts' (2015) sample-size tool for thematic analysis. International Journal of Social Research Methodology, 19(6), 739-743. doi:10.1080/13645579.2016.1195588

Cooner, T. S. (2013). Using Facebook to explore boundary issues for social workers in a networked society: Students' perceptions of learning. British Journal of Social Work, 1-18. doi:10.1093/bjsw/bcs208

de Zúñiga, H. G., \& Valenzuela, S. (2011). The mediating path to a stronger citizenship: Online and offline networks, weak ties, and civic engagement. Communication Research, 38(3), 397-421.

Dombo, E. A., Kays, L., \& Weller, K. (2014). Clinical social work practice and technology: Personal, practical, regulatory, and ethical considerations for the twenty-first century. Social Work in Health Care, 53, 900-919.

Dwyer, S. C., \& Buckle, J. L. (2009). The space between: On being an insider-outsider in qualitative research. International Journal of Qualitative Methods, 8(1), 54-63.

Edwards, H., \& Hoefer, R. (2010). Are social work advocacy groups using Web 2.0 effectively? Journal of Policy Practice, 9, 220-239.

Ellison, B., Lampe, C., Steinfield, C., \& Vitak, J. (2011). With a little help from my friends: How social network sites affect social capital processes. In Z. Papacharissi (Ed.), A networked self: Identity, community, and culture on social network sites (pp. 124-145). New York, NY: Routledge.

Fuchs, C. (2014a). Social media and the public sphere. triple C: Communication, Capitalism and Critique: Journal for a Global Sustainable Information Society, 12(1), 57-101.

Fuchs, C. (2014b). Social media: A critical introduction. London, UK: Sage.

Gerbaudo, P. (2012). Tweets and the streets: Social media and contemporary activism. London, England: Pluto Press.

Graham, T., \& Wright, S. (2014). Discursive equality and everyday talk online: The impact of "superparticipants". Journal of Computer-Mediated Communication, 19(3), 625-642.

Graham, T., Jackson, D., \& Wright, S. (2015). 'We need to get together and make ourselves heard': Everyday online spaces as incubators of political action. Information, Communication \& Society, 1-17. doi:10.1080/1369118x.2015.1094113

Granovetter, M. S. (1973). The strength of weak ties. American Journal of Sociology, 78(6), 1360-1380. doi: $10.1086 / 225469$

Harbeck-Voshel, E., \& Wesala, A. (2015). Social media and social work ethics: Determining best practices in an ambiguous reality. Journal of Social Work Values and Ethics, 12, 67-76. 
Jenkins, H., Clinton, K., Purushotma, R., Robison, A., \& Weigel, M. (2009). Confronting the challenges of participatory culture: Media education for the 21st century. MacArthur Foundation Publication, 1(1), 1-59.

Joyce, M. (Ed.). (2010). Digital activism decoded: The new mechanics of change. New York: International Debate Education Association.

Julien, C. (2015). Bourdieu, social capital and online interaction. Sociology, 49(2), 356-373. doi:10.1177/ 0038038514535862

Kaplan, A. M., \& Haenlein, M. (2010). Users of the world, unite! The challenges and opportunities of socia media. Business Horizons, 53(1), 59-68. doi:10.1016/j. bushor.2009.09.003

Kellsey, D., \& Taylor, A. (2016). The learning wheel: A model of digital pedagogy. Hertfordshire, UK: Critical Publishing.Kimball, E., \& Kim, J. (2013). Virtual boundaries: Ethical considerations for use of social media in social work. Social Work, 58(2), 185-188.

Kolek, E. A., \& Saunders, D. (2008). Online disclosure: An empirical examination of undergraduate Facebook profiles. Journal of Student Affairs Research and Practice, 45(1), 1-25.

Lambert, A. (2016). Intimacy and social capital on Facebook: Beyond the psychological perspective. New Media \& Society, 18(11), 2559-2575. doi: $10.1177 / 1461444815588902$

Langlois, G., Elmer, G., McKelvey, F., \& Devereaux, Z. (2009). Networked publics: The double articulate of codes and politics on Facebook. Canadian Journal of Communication, 34(3), 415-434

Levine, P. (2000). The Internet and civil society. Report from the Institute for Philosophy and Public Policy, 20, 1-9. Retrieved from http://www.puaf.umd.edu/ippp

Megele, C. (2014). eABLE: Embedding social media in academic curriculum as a learning and assessment strategy to enhance students learning and e-professionalism. Innovations in Education and Teaching International, 52, 414-425. doi:10.1080/ 14703297.2014 .890951

Mohan, T., McGregor, H., \& Strano, Z. (1992). Communicating theory and practice (3rd ed.). Marrickville, NSW: Harcourt Brace \& Company

Papacharissi, Z. (2004). Democracy online: Civility, politeness, and the democratic potential of online political discussion groups. New Media \& Society, 6(2), 259-283.

Pink, S., Horst, H., Postill, J., Hjorth, L., Lewis, T., \& Tacchi, J. (2016). Digital ethnography: Principles and practice. London, UK: Sage.

Reamer, F. (2015). Clinical social work in a digital environment: Ethical and risk-management challenges. Clinical Social Work Journal, 43, 120-132. doi:10.1007/ s10615-014-0495-0

Ryan, D., \& Garrett, P. M. (2017). Social work "logged on": Contemporary dilemmas in an evolving "techno-habitat". European Journal of Social Work. doi:10.1080/ 13691457.2016 .1278520

Sage, M., \& Sage, T. (2016). Social media and e-professionalism in child welfare: Policy and practice. Journal of Public Child Welfare, 10(1), 79-95. doi:10.1080/15548732.2015.1099589
Simpson, J. E. (2017). Staying in touch in the digital era: New social work practice. Journal of Technology in Human Services, 35(1), 86-98 doi:10.1080/15228835. 2017.1277908

Sitter, K. C., \& Curnew, A. H. (2016). The application of social media in social work community practice. Social Work Education, 1-13. doi:10.1080/02615479.2015.1131257

Social Workers Registration Board. (2016). Code of conduct. Retrieved from http://swrb.govt.nz/concerns-andinformation/code-of-conduct/

Steyaert, J., \& Gould, N. (2009). Social work and the changing face of the digital divide. British Journal of Social Work, 39(4), 740-753.

Standage, T. (2013). Writing on the wall: Social Media-the first 2,000 years. London, UK: Bloomsbury.

Stanfield, D., \& Beddoe, L. (2016). Social work and socia media in Aotearoa New Zealand: Educating social workers across shifting boundaries of social work identity. Social Work Education, 35(3), 284-296. doi:10. 1080/02615479.2016.1154663

Statistica. (2016). Number of monthly active Facebook users worldwide as of 2nd quarter 2016 (in millions). Retrieved from http://www.statista.com/statistics/264810/numberof-monthly-active-facebook-users-worldwide/

Steinfield, C., Ellison, N. B., \& Lampe, C. (2008). Social capital, self-esteem, and use of online social network sites: A longitudinal analysis. Journal of Applied Developmental Psychology, 29(6), 434-445.

Thomas, G. (2011). A typology for the case study in socia science following a review of definition, discourse, and structure. Qualitative Inquiry, 17(6), 511-521. doi:10.1177/1077800411409884

Tierney, T. F. (2013). Disentangling public space: Social media and internet activism. Thresholds, 82-89.

Valenzuela, S. (2012, July). Protesting in the age of social media: Information, opinion expression and activism in online networks. Paper presented to The $5^{\text {th }}$ Latin American Public Opinion Congress, Bogota, Colombia.

Varnelis, K., \& Friedberg, A. (2008). Place: The networking of public space. Networked Publics, 15-42.

Warren, A. M., Sulaiman, A., \& Jaafar, N. J. (2015). Understanding civic engagement behaviour on Facebook from a social capital theory perspective. Behaviour \& Information Technology, 34(2), 163-175 doi:10.1080/0144929X.2014.934290

Westwood, J. (Ed.). (2014). Social Media in Social Work Education. Northwich, UK: Critical Publishing Ltd.

Willig, I., Waltorp, K., \& Hartley, J. M. (2015). Field theory approaches to new media practices: An introduction and some theoretical considerations. MedieKultur. Journal of Media and Communication Research, 31(58), 1-12.

Wolf, L., \& Goldkind, L. (2016). Digital native meet friendly visitor: A Flexner-inspired call to digital action. Journal of Social Work Education, 1-11. doi:10.1080/10437797.20 16.1174643 